\title{
POLÍTICA DO ETNOCÍDIO E RESISTÊNCIA NAS RETOMADAS KAINGANG NO RIO GRANDE DO SUL'
}

\section{Clémentine Maréchal ${ }^{2}$}

"Ser tudo é ser uma parte. A verdadeira viagem é o retorno." Ursula Le Guin.

\begin{abstract}
Resumo: Esse artigo propõe dar visibilidade à situação territorial atual de três Terras Indígenas Kaingang no norte do Rio Grande do Sul que ainda não foram homologadas pelo Estado brasileiro. Esses três territórios foram retomados nos anos 2000, de forma autônoma pelos Kaingang. Os membros dessas comunidades encontram-se perseguidos pelas elites locais e criminalizadas pelo aparato jurídico do Estado que respalda os interesses econômicos dessas elites. Assim, esse trabalho pretende ressaltar os mecanismos desenvolvidos, tanto pelos meios de comunicação oficiais quanto por representantes do Estado e das organizações ligadas ao agronegócio, que buscam por um lado apagar a memória e a vida indígena nas regiões que hoje controlam, e por outro, deslegitimar, perseguir e criminalizar os Kaingang que ousam desafiá-los. Esses diversos tipos de violência se constituem como uma verdadeira política do etnocídio à qual porém, os Kaingang resistem, empenhando-se a lutar com determinação por recuperar seus territórios, e com eles toda uma serie de relações sociais, econômicas e espirituais que lhes foram expropriadas ao longo dos diversos processos coloniais.
\end{abstract}

Palavras-chaves: Kaingang. Etnocídio. Agronegócio. Meios de Comunicação.

\section{INTRODUÇÃO: UMA BREVE HISTÓRIA DA AÇÃO GOVÉRNAMENTAL COM (CONTRA) OS KÁINGANG}

Os Kaingang conformam um povo de mais de 45000 pessoas que habitam os estados de Rio Grande do Sul, Santa Catarina, Paraná e o sul de São Paulo. Pertencem ao tronco linguístico Jê, assim como os povos Bororo, os Xokleng,

\footnotetext{
1 Esse artigo é uma reelaboração de uma participação da autora na Mesa Redonda: "Tecendo Reexistências" durante a Semana dos Povos Indígenas na UNILA em abril de 2017.

2 Graduada em etnologia na Universidade Paris X-Nanterres. Mestre e doutoranda em antropologia social no PPGAS/UFRGS.Contato:clementine.marechal08@gmail.com
} 
os Kayapó ou os Terena. Antigamente os Kaingang eram seminômades e viviam exclusivamente da pesca, da coleta e da caça (BECKER, 1976), se alimentando principalmente do pinhão, o fruto da araucária, considerada até hoje como sagrada por eles. O pilar da organização social Kaingang reside na divisão dos seres - humanos, não humanos e extra-humanos - que compõem o mundo Kaingang entre duas metades opostas e complementares: Kamé e Kanheru-Kré3.

Os portugueses e as missões jesuíticas invadiram os territórios Kaingang desde o fim do século XVI (MOTA, 1994; LAROQUE, 2000), porém, é sobretudo a partir da metade do século XIX, com a política oficial dos aldeamentos ${ }^{4}$ que toda uma série de relações que os Kaingang desenvolviam com seu território e entre si, vieram a ser modificadas consideravelmente. Os aldeamentos eram administrados por um diretor e por missionários encarregados de uma verdadeira missão civilizatória. Reafirmando uma política da guerra de conquista (SOUZA LIMA. 1995), a política dos aldeamentos buscava controlar os movimentos dos indígenas e inseri-los na produção econômica do país. Sedentarizados, os Kaingang foram forçados a trabalhar em lavouras e a frequentar as primeiras escolas onde o uso do português tornou-se obrigatório e o uso da sua língua nativa, proibido. Mas, um dos maiores objetivos dos aldeamentos foi a "liberação" das terras para a chegada de colonos europeus (FERNANDES, 2003), que desde a segunda década do século XIX foram incentivados pelo império a "povoar" e desenvolver o Brasil 5 .

Em 1910, o Serviço de Proteção dos Índios é criado e se constitui como uma verdadeira instituição total (GOFFMAN, 1968) no seio dos territórios indígenas. O SPI se dividia em 8 Inspetorias Regionais (IR), cada uma responsável pela gestão de diversos "Postos Indígenas" onde um "Chefe de Posto" atuava enquanto administrador do território e dos seus habitantes indígenas (SOUZA LIMA, 1995). Fundamentado no positivismo ${ }^{6}$ e no evolucionismo, os representantes do SPI consideravam que os indígenas deviam ser pacificados e civilizados para serem integrados na sociedade nacional. Porém, o objetivo principal do SPI era

3Para mais detalhes ver Becker (1976), Veiga (2000), Baptista da Silva (2002), Rosa (2005), só para citar alguns.

4 Essa política se torna efetiva a partir de 1845.

5 A resistência dos Kaingang diante da invasão dos colonos europeus em suas terras foi extremamente significativa. Ver Mota (1994).

6 Lembramos que o SPI foi criado sob a influência do Marechal Cândido Rondon que via no SPI uma maneira de pacificar os indígenas, oficializando assim uma política que visaria a "proteção" dos indígenas. Porém, paradoxalmente, a época do SPI acabou se revelando como uma das mais violentas para os povos indígenas do Brasil. Em finais dos anos 60, o SPI foi sujeito a uma Comissão Parlamentar de Inquérito por ter recebido denúncias de corrupção e genocídio. Em 1967, a FUNAI (Fundação Nacional do Índio) assume o controle da gestão dos indígenas. 
transformar os indígenas em trabalhadores nacionais. Assim, homens, mulheres e crianças Kaingang maiores de 10 anos foram forçadas a trabalhar em lavouras e diversas obras públicas (principalmente na construção de estradas) em troca de comida ${ }^{7}$.

Diante desse cenário, muitos Kaingang acabaram se aventurando fora dos PI, preferindo tornar-se peões dos colonos europeus que sujeitarem-se à política civilizatória e extremamente repressiva do $\mathrm{SPI}^{8}$. Essa foi uma política integracionista a serviço do desenvolvimento econômico do país. Os indígenas foram explorados pelo Estado e obrigados a abandonar sua língua e seus costumes que eram considerados um freio à expansão capitalista e uma ameaça à união nacional'.

A ditadura militar exigiu dos Kaingang uma intensificação na sua produtividade. A revolução verde transformou as terras indígenas em verdadeiras empresas rurais de monocultura. Incentivados pelos órgãos institucionais (SPI e a partir de 1967, FUNAI), os territórios Kaingang são arrendados para os fazendeiros da região. Os representantes dos órgãos institucionais jogavam o papel de intermediários entre os indígenas e os fazendeiros, ganhando com isso, considerável soma de dinheiro ${ }^{10}$. Um dos "efeitos perversos" dos arrendamentos de terra foi a consolidação de elites indígenas, escolhidas pelo Chefe do Posto. Esses caciques que passaram a acumular a riqueza produzida pelos arrendamentos fortaleceram seu poder o que gerou uma importante desigualdade no seio das TI. Como exemplo, em 1975, o CIMI (Conselho Missionário Indigenista), num dos seus relatórios afirmou que a Terra Indígena de Nonoai é um cemitério de gente viva.

Esses processos de territorialização (PACHECO DE OLIVEIRA, 1998) que se desenvolveram de forma mais contundente a partir da consolidação do Estado-nação brasileiro e da política indigenista do SPI tiveram impactos profundos no seio das relações sociais, econômicas, espirituais e intersubjetivas dos Kaingang. Nas Terras Indígenas do interior do Rio Grande do Sul ou do Paraná, a maioria dos Kaingang foram acostumados desde a metade dos anos 60 a trabalharem enquanto agricultores (muitas vezes na agricultura intensiva); costumam divertir-se e organizar "bailes" onde tocam ícones da "música do sul" e com as partidas de futebol na televisão. Não significa que Kaingang tenham

\footnotetext{
7 Na memória coletiva dos Kaingang essa época é lembrada como "sistema panelão". Ver Braga (2015) e Irani (2015).

8 Sobre os abusos de poder cometidos pelos funcionários do SPI em tudo o território brasileiro: ver Valente (2017).

9 Especificamente em relação aos Kaingang ver IRANI (2015), BRAGA (2015) e BRINGMANN (2015).

10 Para mais detalhes ver Pozzobom (1999).
} 
sido "aculturados" ou "assimilados" pela sociedade brasileira. Ao se reconhecer enquanto Kaingang e expressar seu pertencimento a uma identidade histórica e social compartilhada, também se articulam com a identidade brasileira e as identidades regionais.

A partir do fim dos anos 1970 os Kaingang iniciaram uma luta pela recuperação dos seus territórios expropriados em diversas empreitadas. No Rio Grande do Sul, o governo Brizola iniciou em 1962 uma reforma agrária que extinguiu várias Terras Indígenas Kaingang como o caso da TI Ventarra, e diminuiu consideravelmente outras, como no caso da TI Serrinha. No sul do Paraná, um acordo entre o governo Lupion e o Ministério da Agricultura/SPI retira 8.975,76 hectares do território de Mangueirinha com a finalidade de dar terra para imigrantes e colonos (CASTRO, 2011, p.59). Logo, em 1961 essa terra será vendida à empresa madeireira Slaviero \& Filhos S/A- Indústria e Comércio de Madeiras.

Organizando-se mediante assembleias ${ }^{11}$ que reuniam lideranças indígenas do sul do Brasil e discutindo estratégias e tácticas de luta, os Kaingang conseguem várias vitórias na recuperação dos seus territórios expropriados. Em 1976, a TI Rio das Cobras no Paraná inicia esse processo de retomada e marca uma primeira vitória. Em 1978, é a TI Nonoai que é recuperada em um processo liderado por Nelson Xangré que até hoje é lembrado como um ícone da luta pela terra pelos Kaingang no Rio Grande do Sul. Lutando no âmbito político e se apropriando das armas jurídicas ${ }^{12}$, os Kaingang apontam ao reconhecimento dos seus direitos originários à terra e dos seus costumes e tradições.

Assim, em 1988, a Constituição brasileira em seu artigo 231, reconhece o direito dos povos indígenas às suas terras:

(...) as por eles habitadas em caráter permanente, as utilizadas para suas atividades produtivas, as imprescindíveis à preservação dos recursos ambientais necessários a seu bem-estar e as necessárias a sua reprodução física e cultural, segundo seus usos, costumes e tradições. (Artigo 231. $\$ 1^{\circ}$. Constituição Federal de 1988).

Diante desse panorama, a FUNAI que então pertencia ao Ministério da Justiça ${ }^{13}$ passa a se encarregar dos processos de identificação, delimitação, demar-

11 Nos referimos por exemplo à VIII Assembleia de Chefes e representantes indígenas que aconteceu em São Miguel (RS) durante o mês de abril de 1977.

12 Nota-se que em 1976, Angelo Kretã, da TI Mangueirinha é eleito primeiro vereador indígena do país.

13 Desde o lo de janeiro de 2019, o presidente Jair Bolsonaro decretou que a FUNAI doravante pertence ao Ministério dos Direitos Humanos e da Família e que perde sua competência de demarcação das Terras Indí- 
cação e homologação das Terras Indígenas. Em relação aos Kaingang, existem hoje 31 Terras Indígenas homologadas ${ }^{14}$ (incluindo as ditas "reservadas"). Outras ainda não foram demarcadas, algumas estão no inicio do processo de demarcação, consideradas pelas instituições como "em identificação", outras já foram declaradas e aguardam pela indenização e relocalização das pessoas que ocupam suas terras ou ainda têm o seu laudo antropológico aprovado pela FUNAI mas não pelo Ministério da Justiça. Com o Parecer 001/2017, mais conhecido como "marco temporal", vários processos de demarcação foram paralisados.

Algumas dessas TI são originarias dos aldeamentos do século XIX e mesmo com uma considerável diminuição, nunca foram ausentes da presença das instituições indigenistas encarregadas da sua gestão (como no caso de Nonoai ou Guarita por exemplo). Em outros casos, os Kaingang foram em diversos momentos, expulsos das suas terras, forçados a integrar outros aldeamentos ou Postos Indígenas. As instituições de gestão dos indígenas abandonaram oficialmente os territórios e estes passaram a serem vendidos para colonos europeus ${ }^{15}$. Porém, esses territórios não desapareceram da memória histórica e coletiva dos Kaingang cujo antepassados os habitavam e percorriam. Assim, a partir dos anos 1990, várias famílias Kaingang se organizaram na empreitada de retomar esses territórios ancestrais, antigamente ocupados pelos seus pais, avós e tataravós que passaram a ser controlados por famílias de colonos europeus que chegaram no sul do Brasil a partir da metade do século XIX e que se tornaram, com um apoio considerável do governo, fazendeiros produtores de soja, milho, feijão, trigo e criadores de gado, aves e suínos.

Respaldados pelos seus direitos constitucionais, os Kaingang decidem acampar nos seus antigos territórios no intuito de pressionar o governo para que demarcasse suas terras. A situação territorial dos Kaingang acampados é permeada por uma série de conflitos com os fazendeiros, mas também, com as instituições que os representam (sindicatos rurais pertencendo à Federação de Agricultura do Rio Grande do Sul - FARSUL) que possuem também o respaldo da população local (comerciantes, funcionários públicos e sobretudo, os meios de comunicação). Nesse cenário, a voz dos Kaingang acampados foi invisibilizada, sua luta

genas, entregando essa responsabilidade ao Ministério da Agricultura (MAPA). Uma manobra política que simplesmente busca paralisar todo os processos de demarcação e homologação das T.I. que encontravam-se em andamento. Após a realização do XV Acampamento Terra Livre do 24 ao 26 de abril de 2019 em Brasília, o presidente da Câmara se comprometeu em trabalhar para desaprovar a Medida Provisória 870.

14 Disponível em <https://terrasindigenas.org.br/pt-br/pesquisa/povo/127>. Acessado em 11/04/2019.

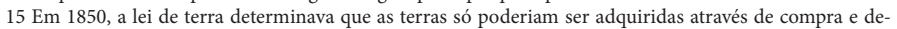
liberava quais seriam as terras devolutas do Império. Inserida num contexto de liberalismo econômico, o objetivo dessa lei era proteger os interesses dos fazendeiros. Em relação ao sul do país, Laroque (2000, p.72) ressalta que essa lei permitiu a redução das terras indígenas sob o pretexto de serem improdutivas. 
considerada ilegítima e os meios de comunicação oficiais, manipulando os fatos e a opinião pública, fortaleceram a animosidade da população local em relação aos Kaingang, assegurando o contínuo rechaço da população à demarcação das Terras Indígenas e reforçando assim o poder das elites políticas e econômicas da região.

Esse artigo propõe dar visibilidade à situação territorial atual de três Terras Indígenas Kaingang. Uma em processo de identificação, outra cujo relatório foi aprovado pela FUNAI e a última que foi declarada e aguarda a indenização dos agricultores presentes no território Kaingang. Todas se encontram na região norte do Rio Grande do Sul. Vale a pena ressaltar que esses três territórios foram retomados nos anos 2000 de forma autônoma pelos Kaingang que se empenham em lutar com dignidade por permanecer neles. As retomadas se fundamentam também na recuperação de uma serie de relações sociais, econômicas e espirituais que foram expropriadas dos Kaingang ao longo dos diversos processos coloniais. Pretendemos ressaltar aqui os mecanismos, desenvolvidos tanto pelos meios de comunicação oficiais quanto por representantes de Estado e das organizações ligadas ao agronegócio, que buscam por um lado, apagar a memória e a vida indígena nas regiões que hoje controlam, e por outro, deslegitimar, perseguir e criminalizar as vozes dos Kaingang que ousam desafiá-los.

\section{VAYKUPRI (CARAZINHO - RS): OS KAINGANG FRENTE ÀS ELITES POLÍTICAS E ECONÔMICAS LOCAIS}

Carazinho é uma cidade de 60.000 habitantes situada no interior do Rio Grande do Sul. A economia da cidade é baseada principalmente na agricultura intensiva. Nota-se a presença de uma sede da multinacional Monsanto a alguns quilômetros da cidade, no município de Não me Toque. As elites econômicas e políticas locais se entrelaçam ao redor do agronegócio como veremos a seguir.

Foi no início dos anos 2000 que algumas famílias Kaingang ocuparam um espaço na BR-386, na entrada da cidade de Carazinho, decididos a retomar uma parte do seu território ancestral. Quando conheci a comunidade em 2013, os laudos antropológicos à demanda dos Kaingang e da FUNAI tinham sido realizados apelando a uma demarcação de 4000 hectares, porém, os Kaingang moravam em menos de 1 hectare aguardando pela demarcação da sua terra. O laudo, embora aprovado pela FUNAI, não tinha sido assinado pelo Ministro da Justiça. Sem sua terra ser demarcada, a assistência governamental por parte da FUNAI e da 
Secretaria de Saúde Especial Indígena (SESAI) estava basicamente escassa. Em baixo de lona, sem saneamento básico nem atendimento à saúde ou escola dentro da comunidade, os Kaingang de Vaykupri encontravam-se numa situação muito precária que iria piorar em julho de 2014 com a emissão de uma reintegração de posse. Essa reintegração foi emitida por Lucia Vera Weber, cunhada do vereador da cidade e membro do sindicato rural de Carazinho associado à FARSUL, Daniel Weber.

Em 2013, entrando na página web da prefeitura, no link "cidade", no sub-link "histórico", achamos um artigo escrito por funcionários do museu Olívio Otto. $\mathrm{O}$ artigo relatava a presença histórica dos indígenas exatamente no território que logo daria lugar a cidade de Carazinho: "Em 1631, na região de Pinheiro Marcado (oeste da cidade atual), foi fundada a primeira aldeia indígena, com o nome de São Carlos do Caapi. [...] Em 1637, o bandeirante português André Fernandes expulsou os últimos missioneiros e indígenas." Porém, entrando de novo na página web da prefeitura uns meses mais adiante, percebemos que o "histórico" da cidade, entre 2013 e 2014 tinha mudado. Após julho de 2014 e a então reintegração de posse de Vera Weber, a história da cidade iniciava em 1872 com a construção da capela e de um povoado. A única referência feita aos indígenas da região é registrada como um perigo a ser combatido, ressaltando assim a "coragem" e "bravura" dos homens que chegaram e fundaram a cidade de Carazinho:

E assim nasceu Carazinho. Com a presença de homens que pertenciam a uma sociedade já desenvolvida, migrando para uma região completamente desabitada e sem nenhum dos confortos conhecidos então. Sabendo do perigo dos índios e da total falta de recursos a que seriam submetidos. ${ }^{16}$

Essa mudança no site da prefeitura não é casualidade. Permite deslegitimar a presença atual dos Kaingang no território. Frente à reintegração de posse, os Kaingang apelaram ao laudo antropológico realizado por especialistas que aponta à presença Kaingang no território muito anterior à chegada dos primeiros europeus assim como à Constituição brasileira. A família Weber porém, poderia usar a "história oficial" (a história relatada na página web da prefeitura) como argumento contra as reivindicações dos Kaingang que poderia legitimar um contra-laudo desfavorável à demarcação de uma T.I. em Carazinho. Para servir seus interesses, as elites econômicas e políticas locais não duvidam em modificar e moldar a história. Além de poder ser usadas em um âmbito jurídico, essas modificações históricas, servem sobretudo de estratégia narrativa para ganhar apoio

16 Disponível em <http://www.carazinho.rs.gov.br/?menu=cidade >. Acessado em 11/04/2019. 
e reconhecimento da população local.

O histórico de Carazinho apresentado no site da prefeitura da cidade nega totalmente os indígenas enquanto habitantes desse território, seja historicamente, considerados como perigo a ser combatido, seja na atualidade, se empenhando em querer expulsá-los da cidade e da região mediante as repetitivas reintegrações de posse. A manipulação histórica, que se elucida através de pequenos exemplos como esse, é o resultado de estratégias políticas que permitem dar legitimidade a processos de criminalização dos indígenas que retomam o território antigamente habitado por eles.

O etnocídio pode se desenvolver sob várias formas, mas segue uma mesma lógica: a de exterminar a diferença (CLASTRES, 2014). No contexto carazinhense - e como é muito comum no interior do Rio Grande do Sul - trata-se de ressaltar e difundir midiaticamente a presença indígena como um perigo ao desenvolvimento econômico da região. Isso é exemplificado nas palavras do presidente da câmara dos vereadores de Carazinho em 2014, Rudi Bombrilla ${ }^{17}$ :

Não sou contra a demarcação para assentamentos indígenas, mas sou totalmente contra a doação de uma nova área em nosso município. Carazinho nunca foi área indígena, e os que aqui estão assentados devem voltar para suas aldeias de origem. Temos uma agricultura forte e produtiva, e não podemos prejudicar nossos agricultores. ${ }^{18}$

É interessante ler na mesma colocação de Rudi Bombrilla uma frase que faz referência à inexistência da presença indígena no lugar enquanto, três palavras adiante, fala em termos de produtividade. Pois a presença indígena, nesse caso, é ressaltada por ser potencialmente um risco aos benefícios e aos lucros do agronegócio. A "correção" do texto na página web da prefeitura é o produto de uma escolha estratégica frente à "ameaça" indígena em Carazinho. Essa escolha estratégica está acompanhada por mecanismos judiciais empregados para criminalizar e deslegitimar a existência indígena na cidade como vimos através das repetitivas reintegrações de posse que os Kaingang receberam.

Ainda vasculhando a página web da prefeitura uma série de afirmações são instrutivas, como um artigo produzido pela imprensa local e publicado no dia 13 de janeiro de 2014 que nos permite refletir sobre os mecanismos de distorção e

17 Esses apontamentos se encontram também em Maréchal (2017).

18 Disponível em <http://www.camaracrz.rs.gov.br/?menu=comunicacao\&sub=noticias\&id=1271 $>$. Acessado em 11/04/2019. 
manipulação utilizados pelos meios de comunicação para servir determinados interesses econômicos, promulgando ódio e mobilizando a população local contra os indígenas na cidade e além dela:

Na tarde da última sexta-feira (10), foi realizada uma reunião na sede do Sindicato Rural de Carazinho, que tratou algumas questões em relação às áreas indígenas do Estado. A reunião contou com a presença do engenheiro agrônomo do gabinete do deputado estadual Luis Carlos Heinze $^{19}$, Ivan Bonetti, do prefeito Renato Süss, do secretário de Desenvolvimento, Leandro Walber, do presidente da Câmara Municipal de Vereadores Rudi Brombilla, dos vereadores Alaor Tomaz, Daniel Weber e Fernando Sant 'Ana, bem como de alguns associados do Sindicato Rural. Durante a reunião, Bonetti esclareceu que está visitando os mais de 30 municípios que têm situação de áreas indígenas, sendo que já foram regularizados mais de 100 mil hectares de áreas no RS, mas esses números ainda podem aumentar. "13\% da área do País é indígena, somando 0,3\% da população”, disse Bonetti. Ele explicou ainda, os critérios adotados para fazer a regularização das áreas, onde estão os itens como remanescente indígena, laudos in memoriam (não há necessidade de comprovação física). Em relação a Carazinho, alertou que já está sendo realizado o mapeamento. Após as explicações dadas pelo engenheiro, foi planejada pelo grupo uma mobilização junto à outras entidades representativas do município, além de mobilizar o comércio local, estudantes e população em geral, para que compreendam o que está acontecendo. "Se não nos unirmos junto aos agricultores, vamos perder ainda mais espaço e a comunidade precisa estar informada sobre o que está acontecendo, por isso, é importante que se faça além de uma mobilização aqui em Carazinho, também a nível nacional" Observou o prefeito. ${ }^{20}$

O alerta lançado pelo prefeito em referência à "invasão" dos indígenas na "sua" cidade está muito relacionado, tanto com as mudanças na página web da prefeitura, como com as reintegrações de posse recebidas pelos Kaingang repetitivamente, desde julho de 2014. ${ }^{21}$ Como vimos, a Constituição Federal de 1988 considera que as terras indígenas legítimas para demarcação são as terras tradicionalmente ocupadas por eles. Apagar os indígenas da história faz parte, na perspectiva dos políticos carazinhenses, de uma estratégia política baseada em

19 Lembramos que Luiz Carlos Heinze, hoje senador do Rio Grande do Sul, tinha declarado numa audiência pública em novembro de 2013 no município de Vicente Dutra que gays, índios e quilombolas não "prestam". Ver: Disponível em <http://gl.globo.com/rs/rio-grande-do-sul/noticia/2014/02/em-video-deputado-diz-que-indios-gays-e-quilombos-nao-prestam.html>. Acessado em 11/04/2019.

20 Disponível em <http://www.carazinho.rs.gov.br/?menu=comunicacao\&sub=noticias\&id=3419 $>$. Acessado em 11/04/2019.

21 Após ter lutado judicialmente contra mais de seis reintegrações de posse, os Kaingang decidiram, em dezembro de 2016, sair da beira da estrada e ocupar o parque estadual de Carazinho. A TI encontra-se hoje na fase de identificação. 
interesses econômicos que permite deslegitimar a presença indígena hoje nos arredores da cidade, e assim, contrapor outra versão histórica daquela apresentada pelos antropólogos nos laudos da FUNAI. Ressaltar os indígenas apenas como um perigo, deslegitimando sua presença na cidade é outra maneira de dizer que eles nunca "moraram tradicionalmente" no território reivindicado.

Essa criminalização é, portanto, apoiada por vários setores político-econômicos na cidade. Com relações de parceria e parentesco imbricadas entre os membros dos diversos setores, existe uma mobilização anti-indígena por parte da elite carazinhense. Essa mobilização acaba eliminando os Kaingang de maneira implícita, deslegitimando, apagando e/ou criminalizando sua existência. Os discursos políticos difundidos na mídia oficial transformam os indígenas em personagens inventados, atinentes a um imaginário colonial. Os mecanismos empregados pela elite local e justificados pela difusão midiática de discursos anti-indígena terminam impossibilitando e boicotando toda forma de relação que os Kaingang tentam criar com diversos outros setores da "sociedade" carazinhense.

Outro mecanismo usado ao serviço do etnocídio é a política do terror (TAUSSIG, 2012). Em Carazinho, as elites locais não deixam de amedrontar os Kaingang quando esses atravessam a estrada que os separa do coração da cidade. As mulheres relatam que sofreram pressão, perseguição e ameaças por parte da mesma Vera Lucia Weber que as denunciou. Me contou Luana ${ }^{22}$ enquanto estávamos conversando sobre a reintegração de posse que tinham recebido, que ela e seus filhos haviam sido alvo de ameaças de morte na praça central de Carazinho.

Distorções históricas e presentes, difamações, criminalizações, ameaças, esses são mecanismos empregados pela elite política e econômica local. A proteção de seus interesses passa obrigatoriamente pela destruição de quem eles consideram (ou de quem se afirmar) como radicalmente diferente, seja negando-os, representando-os como um perigo, expulsando-os ou buscando sua integração forçada no seio da sociedade nacional.

Em 2017, em Carazinho, os Kaingang ainda enfrentam lógicas coloniais etnocidas baseadas e fundamentadas em projetos ligados à expansão capitalista transnacional que, para realizar-se, provocam a continua subalternização de outras vozes e outros modos de vida. Os representantes governamentais da região sul do país escolhem encerrar e difundir uma ideia do "índio" reduzida a uma imagem de "perigo" totalmente distanciada do mundo moderno civilizado, for-

22 Por medidas de segurança e proteção da pessoa envolvida nessa testemunha, decidimos trocar o seu nome. 
talecendo assim uma clivagem étnica que tem como objetivo fortalecer o racismo que ao ser difundido e reproduzido no seio da sociedade civil, assegura a proteção dos interesses econômicos e políticos das elites.

Porém, é importante ressaltar que essa ideologia do progresso expressada pela atuação das elites locais entra em choque com visões do mundo e práticas territoriais, sociais e econômicas indígenas que se diferenciam dessa ideologia. É também por isso - porque as demandas dos Kaingang reafirmam também o direito à diferença - que sua presença e suas demandas na cidade são constantemente negadas e/ou apagadas.

\section{VOTOURO/KANDÓIA (FAXINALZINHO - RS): A PRÁTICA COTIDIANA DO ETNOCÍDIO}

No início dos anos 2000 uma mulher Kaingang de 80 anos, Maria Kensho Kandóia, estimula seus filhos para que retomassem o território onde ela nasceu. Junto a outras famílias, os parentes de Kensho se juntaram e recuperaram uma parcela do território que lhes tinha sido retirada há mais de 70 anos atrás. As famílias Kaingang em 1923 tinham sido levadas à força pelo então fiscal dos índios e chefe da inspetoria de terras de Erechim, Osório Torres para a atual TI Votouro (município de Benjamin Constant do Sul). O pretexto para retirar os Kaingang do seu território tem sua origem na "Revolução de 1923" na qual os Chimangos e Maragatos se enfrentaram. Osório Torres "aproveitou" a oportunidade e instalou uma casa e uma fazenda que até hoje é propriedade de sua família.

Incentivados por Maria Kensho, seus filhos e netos se organizaram com outras famílias Kaingang para acampar no território expropriado há 80 anos atrás e logo iniciaram um processo de demarcação das suas terras via o apoio da FUNAI e do CIMI. Os estudos foram realizados por vários antropólogos e em 2003, o laudo antropológico foi aprovado pela FUNAI que o repassou para o Ministro da Justiça que o reprovou. O relatório foi corregido e enviado novamente e durante aproximadamente 10 anos, os Kaingang não obtiveram resposta de parte do ministro. Em 2014, o então Ministro da Justiça José Eduardo Cardozo tinha se comprometido com as lideranças Kaingang a "realizar uma reunião de diálogo com a finalidade de dar prosseguimento aos processos de demarcação de terras do RS, entre o Ministério da Justiça, Governo do Estado do Rio Grande do Sul, caciques/lideranças indígenas e agricultores no dia 5 de abril de 201423." Espe-

23 Extrato da "Memória de reunião com os caciques e lideranças Kaingang do Rio Grande do Sul", assinado 
rando ansiosos pela reunião, os Kaingang ficaram decepcionados, pois o Ministro cancelou a reunião e a adiou para o dia 12 de abril, também cancelada.

Indignada com a situação, a comunidade realizou um protesto bloqueando a estrada que liga Benjamin Constant a Faxinalzinho em finais de abril. Durante o protesto, um agricultor e dois dos seus agregados que dirigiam um caminhão que transportava ração para animais não respeitaram o protesto dos Kaingang. Decidiram então "furar" o bloqueio, cortando com motosserra os troncos das árvores colocados na estrada. $\mathrm{O}$ conflito se acirrou e os colonos acabaram sequestrando um jovem Kaingang, apontando uma arma na sua direção. Horas mais tarde, os dois colonos Anderson e Alcimar de Souza foram encontrados mortos.

No dia 9 de maio de 2014, duas semanas após a morte dos colonos, as lideranças Kaingang da comunidade de Votouro/Kandóia foram convocadas a uma reunião de "conciliação" no centro cultural de Faxinalzinho. A presença de agentes da FUNAI não impediu que a Brigada Militar (BM) prendesse cinco lideranças e as levasse para a superintendência da Polícia Federal (PF), em Porto Alegre. Os cinco Kaingang permaneceram presos até o dia 21 de junho de 2014 no presídio de Jacuí, em Charqueadas (RS).

A operação foi comandada pelo delegado Mario Luiz Vieira, que afirmou na impressa local ${ }^{24}$ que: "se trata de um caso de homicídio qualificado e não de demarcação de terras", e que a prisão das lideranças indígenas foi: "o presente de Dia das Mães para a mãe dos irmãos mortos pelos indígenas ${ }^{25}$ ". Não é casualidade que os jornalistas da rádio Uirapuru insistam em separar a morte dos "agricultores" dos processos de demarcação de terras. Aquelas mortes são tratadas como fatos isolados, descontextualizadas do processo histórico no qual se inscrevem os Kaingang e dessa maneira, a manipulação midiática libera de toda responsabilidade os órgãos governamentais dos conflitos no interior do Rio Grande do Sul. A culpa é colocada nos indígenas, com o pretexto de que sejam tratados como qualquer "civil"26. O entrelaçamento da mídia local com o agronegócio e o setor político é, como em Carazinho, impactante. Na mesma matéria, o jornalista afir-

pelo Ministro de Justiça, José Eduardo Cardozo, em 19 de março de 2014. Documento fotocopiado entregue à autora pelos Kaingang de Votouro/Kandóia.

24 As testemunhas foram retiradas do jornal radio uirapuru. Disponível em <http://www.radiouirapuru. com.br/regiao/23222/policia+federal+prende+indios+acusados+de+matar+agricultores+em+faxinalzin

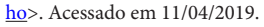

25 Ver Pronunciamento da Comunidade Kaingang de Votouro/Kandóia (2014)

26 "O delegado explicou que foram identificados seis veículos que saíram do acampamento indígena na noite do crime e todos os tripulantes participaram dos assassinatos. Ele destacou que após as prisões o inquérito vai ser feito e mais envolvidos serão identificados e presos. Ele ressaltou que os índios estão sendo tratados como civis e a lei fará seu papel, independente de quem seja." Disponível em <http://www.radiouirapuru. com.br/regiao/23222/policia+federal+prende+indios+acusados+de+matar+agricultores+em+faxinalzinho $>$. Acessado em 11/04/2019. 
ma: "O deputado Federal Luiz Carlos Heinze destacou que a ação só foi possível depois que a imprensa e especialmente a Rádio Uirapuru e o setor político se uniram em pressão para que justiça fosse feita [...]", assim como: "O deputado frisou que a luta continua para que os agricultores não percam suas terras."

Por um lado, quando dois agricultores são encontrados mortos, a imprensa trata o caso como um fato isolado das injustiças vividas pelos Kaingang, notadamente a paralização dos processos de demarcação das suas terras. Por outro, quando os mesmos dois agricultores sequestram um jovem indígena ameaçando-o com uma arma apontada na cabeça, os meios de comunicação oficiais invisibilizam o acontecimento ou indiretamente legitimam qualquer ação dos agricultores em relação aos indígenas "para que os agricultores não percam suas terras".

A atuação da mídia local e regional na difusão de ideias anti-indígenas tem como objetivo reforçar certos ideais e valores, reificando a propriedade privada e o agronegócio. Nessas matérias, a versão dos Kaingang foi totalmente apagada, assim como a atuação violenta dos policiais presentes na operação. Recortando e selecionando os fatos acontecidos, os jornalistas manipulam os sentimentos provocados nos leitores, reforçando assim os ideais e valores favoráveis aos interesses da elite política e econômica local, regional e nacional.

O clima de terror vivido na cidade após a morte dos dois agricultores ${ }^{27}$ foi gerado em grande parte pela distorção dos acontecimentos e o enfoque nas palavras de quem foi considerado naquele momento como "vítima". O prefeito de Faxinalzinho, Selso Pelin, declarou pela rádio Uirapuru (artigo que logo foi difundido pela Zero Hora no dia 9 de maio de 2014) que tinha saído da cidade por medo. Esse clima desembocou num sentimento de terror quanto aos "índios", multiplicado e difundido em toda a região, colocando-lhes mais uma vez na posição de entes perigosos que poderiam pôr em risco a cidade de Faxinalzinho. A título de exemplo, nota-se aqui a declaração do prefeito do município de Faxinalzinho Selso Pelin:

Se criou uma situação ridícula. O governo estadual trouxe uma comitiva para negociar a paz. Acontece que no decorrer da reunião, a polícia prendeu o cacique Deoclides. Eu saí da cidade para não ser linchado. Os índios estão revoltados, dizem que eles estão vindo de outros lugares, armados, para destruir a cidade. (Selso Pelin, 9 de maio de 2014, rádio Uirapuru).

27 A cidade foi paralisada durante quase 2 semanas. O prefeito fugiu da cidade, as escolas e mercados permaneceram fechados. Além disso, os Kaingang foram cotidianamente hostilizados a cada passo que deram fora da comunidade. 
Cria-se através da mídia corporativa uma separação entre o "bom trabalhador produtivista" e o "índio bandido" com o intuito de formar opiniões e fortalecer preconceitos.

As experiências de violência física, ideológica, psicológica e simbólica vividas pelas famílias Kaingang da comunidade de Votouro/Kandóia no momento da prisão das suas lideranças e nos dias, semanas e meses que seguiram, foram totalmente ignoradas pelos jornalistas que sequer se aproximaram da comunidade. Os policiais puderam atuar de forma violenta, colocando, por exemplo, uma arma na cabeça de uma criança que chorava, proibindo os Kaingang em falar na sua língua, insultando os Kaingang durante a detenção das lideranças com, segundo eles, "brincadeiras" do tipo: "esse é o seu presente do Dia das Mães". Ofereceram também dinheiro a uma jovem de treze anos na saída da escola em troca de informações. Estes mesmos policiais foram tratados como heróis pela mídia local, e os "agricultores" que sequestraram um dos filhos da comunidade como vítimas $^{28}$. A mídia, colaborando com as políticas coloniais, torna-se um motor de facilitação e acobertamento do etnocídio no sul do Brasil e deve ser considerada como mais um mecanismo de controle ao serviço dos interesses do agronegócio.

Em 17 de novembro de 2014, a comunidade de Kandóia foi invadida por um efetivo de guerra do Estado brasileiro com a aprovação da população local. Um verdadeiro cerco militar foi armado contra esta comunidade. Na operação, que recebeu o nome de "Operação Kandóia", policiais e peritos invadiram casas às 6 horas da manhã, e à força coletaram amostras de sangue e saliva de todas as pessoas da comunidade. Nesta operação, que aconteceu sem qualquer mandado, todos os homens e adolescentes foram fichados e fotografados ${ }^{29}$.

28 "Depois das prisões, passamos a ficar totalmente isolados e perseguidos pela Polícia Federal. Os homens não podem sair da aldeia - nem para trabalhar e nem mesmo para ir ao mercado - porque a polícia está parando e entrando nos ônibus e intimando as pessoas, criando medo. [...] Esse abuso de autoridade por parte da polícia se repercutiu inclusive nas escolas. Na escola da Terra Indígena de Votouro/Benjamin Constant, os policiais entraram na sala de aula e bateram em um professor indígena na frente das crianças, para tirar informações sobre o ocorrido. Quando os indígenas pediram o mandato para fazer isso, os policiais disseram que não precisava de nada. Em outra escola, em Faxinalzinho, uma pessoa ofereceu 500 reais para que uma menina de treze anos desse informações. [...] A Polícia Federal também passou a fazer rondas em volta do nosso acampamento, e mesmo dentro dele, para intimidar-nos. Tivemos, assim, que cercar a aldeia e conversar com as crianças porque elas ficaram com muito medo: cada vez que veem uma pessoa branca, saem correndo." Ver: Comunidade Kandóia/Votouro (2015).

29 Disponível em $\leq$ http://rdplanalto.com/noticias/7762/operacao-kandoia-policia-federal-apresenta-balanco-do-trabalho-em-faxinalzinho $>$ e $<$ http://www.dpf.gov.br/agencia/noticias/2014/11/pf-cumpre-mandados-de-busca-e-apreensao-para-apurar-autoria-de-homicidios $>$. Acessados em 11/04/2019. 


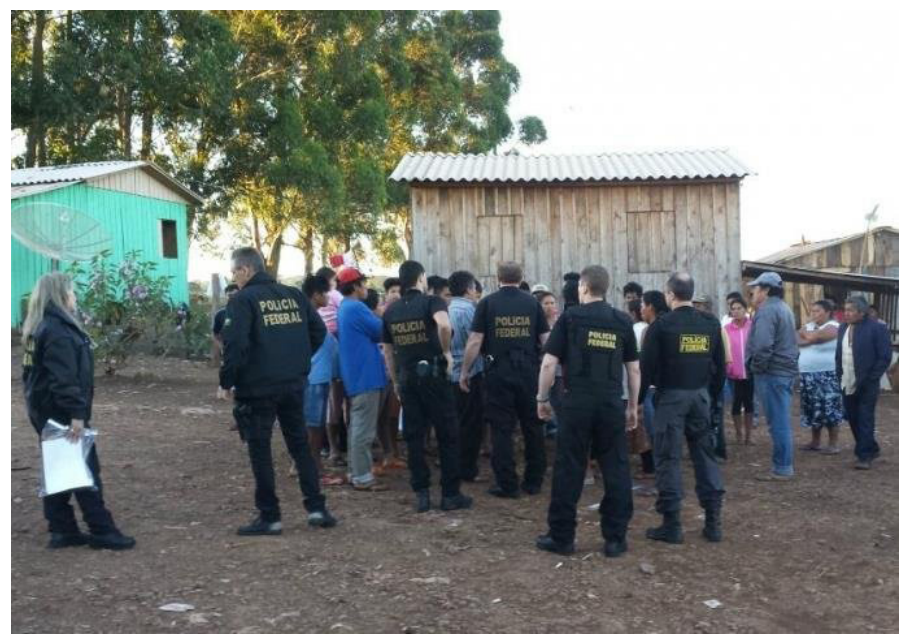

“Operação Kandóia”. Votouro/Kandóia, novembro de 2014. ${ }^{30}$

A morte de dois agricultores é vista, pois, antes de tudo, como um ataque desestabilizador à nação e com isso, atinge os valores que sustentam essa identidade: a produtividade, o capitalismo, a propriedade e a "branquitude". Casos de indígenas sendo mortos por jagunços, pistoleiros, fazendeiros ou policiais são extremamente numerosos. Em 2014, um relatório do CIMI contabiliza 138 assassinatos de indígenas no ano, porém nenhum desses casos recebe tanta atenção por parte da imprensa corporativa. Quem lembra de Vitor Kaingang, criança de dois anos que foi degolada na rodoviária de Imbituba (SC) no verão de 2015? Quem ouviu falar das perseguições à comunidade de Campo do Meio (RS) onde várias casas foram baleadas e onde o antigo vice cacique Isaías da Rosa foi atingido por um tiro nas costas enquanto viajava de carro?

Ainda, no município de Faxinalzinho, são também as pessoas que se solidarizam com os Kaingang que são alvos de violência por parte dos fazendeiros. Antônio Tonatto é vizinho da comunidade, ele cedeu um pedaço do seu terreno para os Kaingang se instalarem. Consciente da legitimidade da luta dos Kaingang, o agricultor os apoia desde que decidiram retornar ao seu território an-

30 Disponível em $\leq$ http://www.radioguaiba.com.br/noticia/faxinalzinho-pf-colhe-material-genetico-de-indios-para-investigar-morte-de-irmaos-agricultores/>. Acessado em 11/04/2019. 
cestral. Em consequência desse apoio, a casa de Antônio foi alvo de ataques com armas de fogo em várias ocasiões. Além disso, ele relata que recebe constantes ligações com ameaças de morte por parte dos fazendeiros locais. Em abril de 2019, os Kaingang de Votouro/Kandóia me relataram que inclusive a nova médica que vem atender a comunidade foi agredida pelos colonos que a trancaram na estrada no intuito de dissuadi-la a não ir trabalhar na comunidade Kaingang. Os casos de violência relatados são inumeráveis. Os Kaingang são constantemente ameaçados cada vez que eles saem dos dois hectares nos quais hoje estão morando, esperando a demarcação das suas terras. Uma menina Kaingang de 13 anos foi espancada quase até morte enquanto voltava de uma coleta de bergamotas em uma das fazendas vizinhas.

Outra forma de violência vivida pela comunidade de Votouro/Kandóia é relacionada com a espoliação do seu território ancestral. Em 2014, as mulheres relataram que a prefeitura obrigou os Kaingang a desenterrar os mortos que tinham sido sepultados em um espaço de terra fora dos dois hectares permitidos.

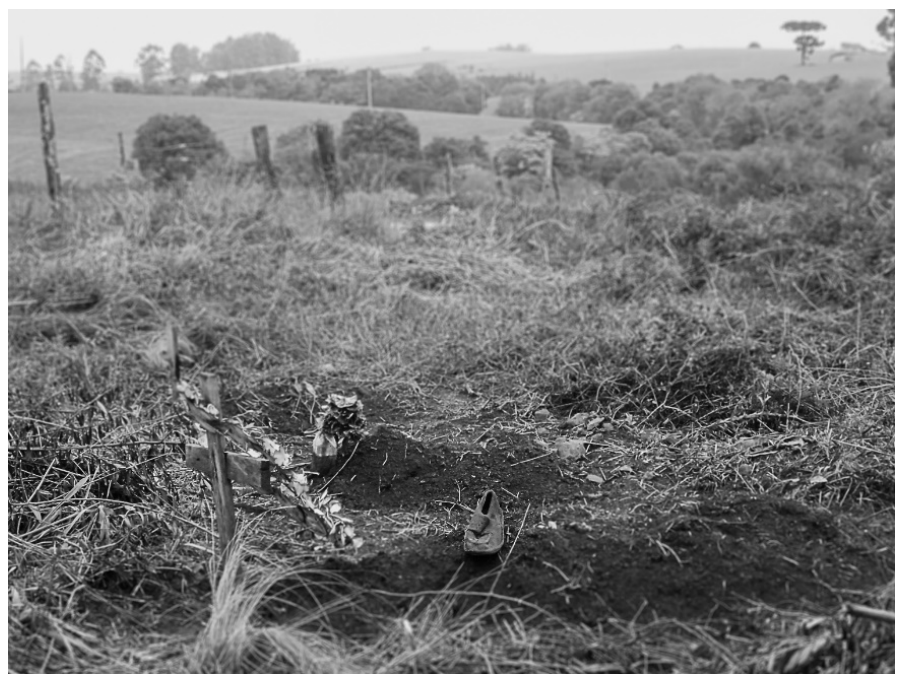

Cemitério Kaingang. TI Votouro/Kandóia, junho de 2014. Fotografia da autora. 
Nesse mesmo plano de violência, os fazendeiros se empenham em cortar os últimos recantos de floresta que permitem aos Kaingang desenvolver atividades socioeconômicas como a fabricação do seu artesanato. O rio goj yenha (água que treme) que passa pela comunidade e onde nos primeiros anos da retomada, os Kaingang tomavam banho e pescavam, foi envenenado com diversos tipos de lixos como por exemplo fezes de porco e cachorros mortos. Essa violência etnocida é particularmente perversa pois atinge o profundo das relações socio-cosmólogicas que os Kaingang desenvolvem com seu território. Além disso, uma outra forma de violência tem a ver, como em Carazinho, com o apagamento da presença Kaingang no território. Enquanto em Carazinho esse apagamento se expressava através de documentos oficiais e históricos, em Votouro/Kandóia, esse apagamento passa pela destruição física dos lugares da memória histórica dos Kaingang. O deslocamento forçado dos defuntos Kaingang é um exemplo, porém, não é o único. Shen, esposa de Deoclides de Paula, cacique da comunidade me relatou que há uns anos, enquanto os antropólogos estavam redigindo o relatório de demarcação, os fazendeiros cortaram a araucária conhecida entre os Kaingang como a araucária onde o antigo cacique Votouro residia nas primeiras décadas do século XIX. Na memória dos Kaingang, essa árvore expressava sua relação ancestral com o território, o vínculo atual com seus antepassados que habitavam esses territórios quando ainda encontravam-se cobertos de floresta. Não é casualidade então, se os fazendeiros se empenham em destruir esses espaços de memória, buscando apagar, exterminar toda presença indígena, seja ela física-material ou imaterial, no local.

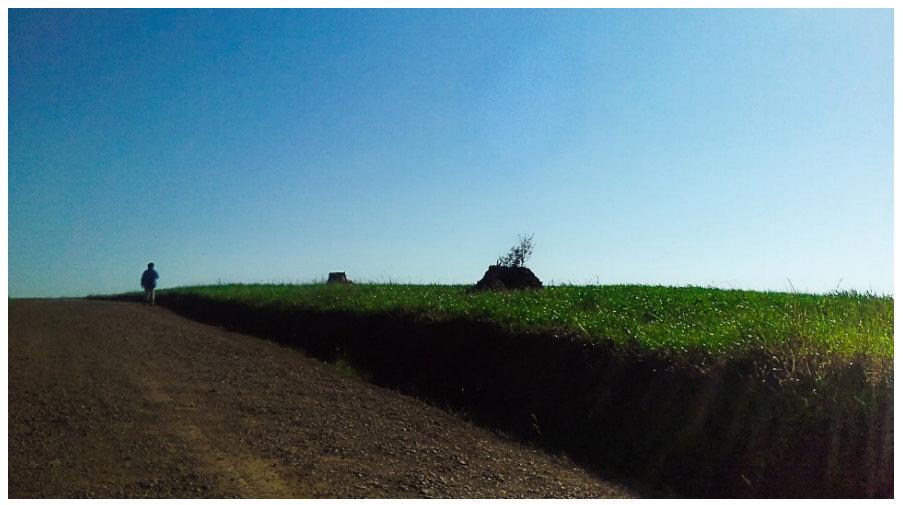


Araucárias cortadas pelos colonos. Lugar sagrado pelos Kaingang: sitio onde o antigo cacique Votouro residia por volta da metade do século XIX. Fotografia da autora, agosto de 2017, TI Votouro/Kandóia.

Os dois exemplos apresentados até agora expressaram formas de violência física, simbólica e ideológica desenvolvidas por elites econômicas regionais cuja atuação etnocida é totalmente respaldada num plano político e judicial. São situações territoriais de conflito nas quais as vozes dos indígenas nunca são ouvidas. Invisibilizados, perseguidos e criminalizados, os Kaingang que lutam pela demarcação das suas terras são considerados pelos políticos como um freio ao desenvolvimento do país. Esses últimos se negam em reconhecer, na prática, outros modos de relacionar-se com o território que diferem de uma objetificação e exploração desenfreada da terra no prol do enriquecimento.

A esses dois exemplos, deveríamos adicionar a repressão policial acontecida no Acampamento de Retomada de Passo Grande da Forquilha (Sananduva - RS) em novembro de 2016. Numa nova operação policial, mais de 180 homens armados, helicópteros, cães e cavalaria foram enviadas no acampamento. Foram presas 8 pessoas, 5 Kaingang e 3 pequenos agricultores em Sananduva e Cacique Doble. As prisões foram decretadas em relação a um incêndio que teria destruído as plantações de soja dos fazendeiros da região no dia 20 de novembro. Em consequência dos incêndios, o prefeito da cidade de Sananduva, Leovir Benedetti decreta o estado de calamidade pública. Os Kaingang e os agricultores foram acusados pelos crimes de ameaça, extorsão, organização criminosa e dano ao patrimônio contra fazendeiros da região ${ }^{31}$. Os Kaingang afirmaram que o incêndio teria sido tudo uma montagem por parte dos próprios fazendeiros, mas até hoje, a justiça continua perseguindo as lideranças dessa comunidade.

\section{KANHGÁG AG GOJ (RIO DOS ÍNDIOS, VICENTE DUTRA - RS): RETOMADA E RUMO À AUTONOMIA}

Os Kaingang estão enfrentando cada vez mais o agronegócio ou outros empreendimentos que, como ressaltou em uma reunião com o presidente da $\mathrm{FU}$ NAI em abril de 2019 o cacique Luís Salvador da TI Kanhgág ag Goj: "ferrem a vida social dos povos indígenas." A vida social almejada pelos Kaingang dessa comunidade tem a ver com a retomada junto com o seu território, de toda uma

\footnotetext{
31Disponíveis $\quad \leq$ http://racismoambiental.net.br/2017/01/24/grupo-kaingang-segue-preso-dois-meses-depois-de-operacao-de-guerra-articulada-por-ruralistas/> e <https://www.noticiasagricolas.com.br/noticias/questoes-indigenas/182717-indigenas-incendeiam-lavouras-em-represalia-a-prisoes-no-norte-do-rs. html\#.XM30lNhrzIV>. Acessados em 11/04/2019.
} 
série de relações nele imbricadas que permitem o fortalecimento do seu tecido social. Assim, o futuro aspirado pelos Kaingang que sonham com terem a terra demarcada, e nela poder reflorestar as matas, despoluir os rios, criar projetos de "agrofloresta", demanda uma mudança radical do modelo econômico atual.

A Terra Indígena Kanghág ag Goj (Rio dos índios) está declarada, porém, a comunidade aguarda há mais de 8 anos a sua homologação. Para isso se concretizar, o Ministério da Agricultura Pecuária e Abastecimento (MAPA) ${ }^{32}$ deveria liberar a verba para a indenização dos agricultores e sua relocalização em outras terras. A comunidade está situada no coração do município de Vicente Dutra e retomou em 2005 o balneário municipal da cidade, dividindo o espaço com seus moradores, temporários ou permanentes. Porém notadamente desde 2013, tensões entre colonos e Kaingang se acirraram na cidade. Alguns seguranças do balneário, descontentes com a presença dos Kaingang no campo de futebol do balneário, atiraram com armas de fogo em direção aos Kaingang que, para sobreviver, se defenderam. No protesto realizado pelos Kaingang, seguranças do balneário e colonos colocaram fogo nas faixas reivindicatórias dos Kaingang. Porém, mais uma vez, os carrascos foram colocados na imprensa regional como vítimas. O título do jornal Zero Hora dizia "Vigilante do internado foi agredido por índios e segue internado no hospital". Como no caso de Carazinho e Faxinalzinho, em Vicente Dutra, a mídia oficial recorta a realidade, manipula fatos e invisibiliza outros no intuito de favorecer os interesses de quem a financia.

Em novembro de 2014, o professor bilíngue Davi Limeira de Oliveira, de 22 anos foi assassinado de uma facada nas costas no município de Vicente Dutra. A imprensa relatou isso como uma "briga de bar". Deixamos aqui a reportagem completa publicada na rádio planalto que a retirou do blog de opinião "Questão Indígena”, uma página web declaradamente anti-indígena:

O índio Kaigangue, Davi Limeira de Oliveira, de 22 anos, morreu na madrugada de hoje em Vicente Dutra, no Rio Grande do Sul. Oliveira estava em uma festa quanto por volta de $1 \mathrm{~h}$ da manhã se envolveu em briga generalizada e foi esfaqueado, vindo a falecer em seguida.

O conflito de Vicente Dutra é o segundo entre índios Kaigangues no Rio Grande do Sul.

No final de semana dois grupos rivais de índios se enfrentaram com facões durante uma partida de futebol em Mato Castelhano ${ }^{33}$.

\footnotetext{
32 Até o primeiro de janeiro de 2019, o Ministério da Justiça estava encarregado de assinar a homologação das TI e o INCRA e a FUNAI disponham de recursos para a indenização dos agricultores.

33 Disponível em $\leq$ http://rdplanalto.com/noticias/7641/novo-conflito-com-indigena-termina-com--um-morto-em-vicente-dutra>. Acessado em 11/04/2019.
} 
Primeiramente, é de ressaltar que somente quatro linhas são dedicadas à morte do jovem Kaingang enquanto a morte dos dois colonos em Faxinalzinho foi publicada em todos os jornais da região, inclusive há um ano da morte dos colonos a rede Globo publicou uma reportagem dando mais uma vez voz aos parentes dos fazendeiros, invisibilizando a versão dos Kaingang e apontando a uma falta de "justiça" ${ }^{34}$. Além disso, a reportagem da rádio planalto não especifica que Davi Limeira de Oliveira foi assassinado por um não indígena, aliás, até deixa o leitor intuir que a causa da sua morte residiria em conflitos internos entre os mesmos Kaingang, usando para isso, um fato totalmente alheio aos acontecimentos: um confronto em Mato Castelhano - a 240 quilômetros de Vicente Dutra - entre dois grupos Kaingang.

Quando são dois colonos brancos que morrem, o fato é considerado como consequência dos conflitos entre indígenas e agricultores e os Kaingang são colocados como seres violentos. Porém, quando um indígena - que já tinha sido ameaçado anteriormente de morte pelos colonos da região - é assassinado de uma facada nas costas, o fato é relatado como uma mera "briga de bar", reforçando assim estereótipos antiquados que categorizam o índio de "briguento e bêbado".

Resumindo, a responsabilidade da morte dos colonos em Faxinalzinho é colocada a priori nas costas dos Kaingang, sem que nenhum processo investigativo tenha sido sequer iniciado, enquanto a responsabilidade da morte de um jovem Kaingang em Vicente Dutra recai também nas costas dos próprios indígenas, descaracterizando-a dos conflitos fundiários que permeiam as relações interétnicas na região.

Esses exemplos apontam ao papel da imprensa que fortalece a opinião de uma sociedade presa em uma matriz colonial que classifica e hierarquiza seus membros em relação a critérios como o da raça ${ }^{35}$. Dessa maneira, as reportagens veiculadas pela mídia regional apontam a uma diferenciação de valor entre a vida de um colono branco e a de um indígena. A vida do indígena é considerada historicamente como menos importante que a vida de um branco. A imprensa, expressando essa hierarquia através das suas reportagens reproduz e reatualiza relações hierárquicas baseada numa classificação social que se origina na formação da estrutura de uma sociedade colonial.

Porém, a resistência das comunidades Kaingang nas retomadas de terra é extremamente contundente. A determinação com a qual seguem sua luta en-

34 Disponível em <http://gl.globo.com/rs/rio-grande-do-sul/rbs-noticias/videos/t/edicoes/v/morte-de-agricultores-em-faxinalzinho-rs-completa-um-ano/4153693/>. Acessado em 11/04/2019. 35 Ver Quijano (1992). 
frentando lógicas etnocidas e a reatualização de processos coloniais em vigor tem muito para nos ensinar. Em julho de 2016, os Kaingang da comunidade Kanhgág ag Goj iniciaram um processo de retomada das suas terras de maneira autônoma. Após vários anos de espera pelo Ministro da Justiça autorizar a indenização e a relocalização dos agricultores que estão ocupando as terras Kaingang, eles decidiram retomar suas terras e construir suas casas no território recuperado.

Como nenhuma promessa de parte do Ministério da Justiça tinha sido cumprida, os Kaingang decidiram se organizar para eles mesmos fazerem frente aos agricultores que ocupavam suas terras. Iniciaram a retomada de forma autônoma começando pela terra que até então pertencia ao fazendeiro e prefeito do município de Palmitos (SC), Dair Jocely Enge. Chamaram seus parentes para que os apoiassem a retomar suas terras como antigamente seus antepassados faziam. Muitos chegaram de outras comunidades dispostos a lutar. Os conselhos na beira do fogo propiciavam a lembrança de alianças antigas entre seus antepassados, a memória das lideranças combativas que já tinham falecido tornava-se palavras nas bocas dos guerreiros mais novos. Falava-se de Augusto Opë da Silva, de Nelson Xangré, de Angêlo Kretã...

A retomada aconteceu sem problemas, novas casas foram construídas no território recuperado. A comunidade decidiu plantar mais de 4000 pés de araucária no intuito de reflorestar o território com a árvore ancestral dos Kaingang. Hoje, o cacique Luís Salvador Saci tem como objetivo a criação de um plano de gestão ambiental no território do seu povo. O sonho de Saci, conforme nos relatou é "de não depender de mais ninguém, de ter nossa autonomia." A retomada, para Luís Salvador Saci aponta a romper também com a matriz colonial. Não se trata simplesmente de uma retomada da terra no sentido de "posse" da terra. Retomar a terra é para Luís Salvador um caminho para fortalecer a sua "vida social", recriar e melhorar as relações com os seres da floresta, apontando por exemplo ao nascimento ou à formação de um/a novo/a kujà (xamã) na comunidade. Enfim, a retomada de Kanhgág ag Goj aponta a uma retomada do modo de viver Kaingang kanhgág jykre para que, seguindo as palavras de Luís Salvador, este (re) construa seu caminho cada vez mais longe das garras do capitalismo. 


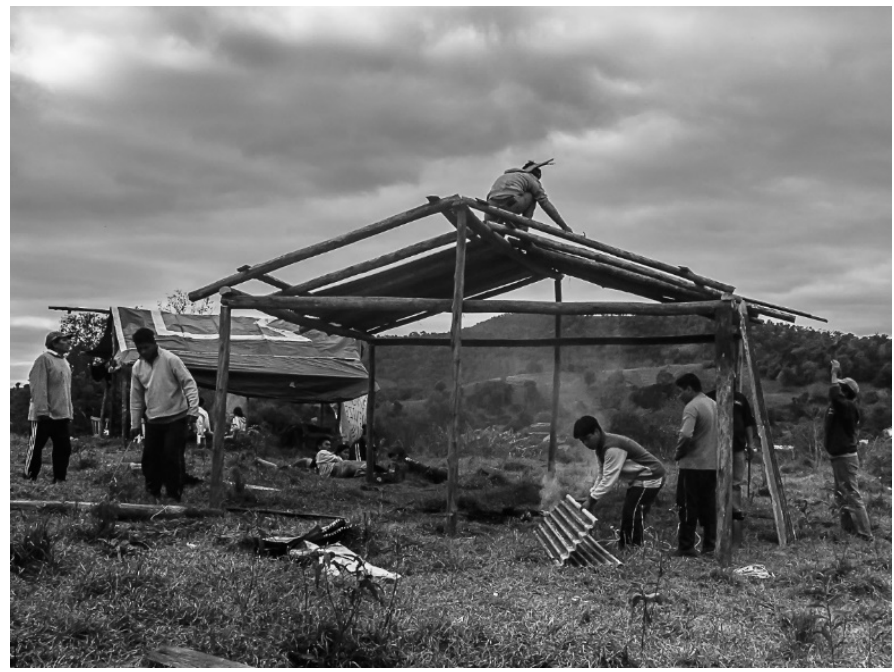

Construção de uma casa na nova retomada. TI Kanhgág ag Goj, julho de 2016. Fotografia da autora.

\section{CONSIDERAÇÕES FINAIS}

As três situações territoriais aqui trazidas exemplificam a política do etnocídio vivida pelas comunidades Kaingang acampadas no norte do Rio Grande do Sul. Estas três comunidades se enfrentam diariamente a um racismo respaldado pelas instituições políticas regionais e fomentado pelos meios de comunicação oficiais. Essa política do etnocídio se expressa na tentativa de apagar a memória e a presença indígena na região usando diversos mecanismos, todos respaldados por instituições jurídicas e políticas ligadas ao governo do Rio Grande do Sul. Entre esses mecanismos encontra-se a manipulação e o apagamento de fatos históricos, a identificação dos indígenas enquanto "ameaça" para o povo brasileiro e uma consequente repressão política que quando convém invisibiliza suas lutas pela demarcação das suas terras - como no caso do assassinato de Davi Limeira de Oliveira - e quando não, coloca os indígenas e suas lutas como empecilhos perigosos para a estabilidade do país - como no caso da morte dos colonos em 
Faxinalzinho ou da retomada em Carazinho. Hoje, o cacique da comunidade de Votouro/Kandóia, Deoclides de Paula, encontra-se impossibilitado de participar de reuniões ou protestos fora da sua comunidade sob a ameaça de ser preso. Ainda 7 lideranças dessa comunidade encontram-se sob medidas cautelares que os impedem fazer escutar sua voz e sua versão dos fatos. Essas medidas cautelares têm como objetivo, mais que imobilizar indivíduos, paralisar uma luta legitima pela demarcação das suas terras.

O entrelaçamento dos representantes políticos (vereadores, senadores e deputados) com os interesses econômicos dos empreendimentos agrícolas foi ressaltado claramente ao longo desse artigo. Este entrelaçamento permeia pois a política etnocida que se desenvolve com (contra) os povos indígenas no sul do Brasil desde a construção do Estado-Nação brasileiro. Outros mecanismos que, por falta de espaço, não abordamos aqui ${ }^{36}$ - também permeiam essa política do etnocídio que visa a desintegração e o desmembramento das especificidades sociais, culturais, econômicas e culturais de cada povo. No entanto, a política do etnocídio nunca chegou a cumprir seu objetivo. Bem ao contrário, no cenário atual, os povos indígenas compõem a única frente de resistência contundente ao governo de ultradireita de Jair Bolsonaro. Atuando nos seus territórios, retomando de forma autônoma suas terras ou manifestando-se frente as autoridades políticas (locais e nacionais) com determinação, a luta dos povos indígenas se constrói como um exemplo de resistência anticolonial e anticapitalista para todo o povo brasileiro ${ }^{37}$.

\section{REFERÊNCIAS}

BAPTISTA DA SILVA, Sergio. Dualismo e cosmologia Kaingang: o xamã e o domínio da floresta. Horizontes Antropológicos, Porto Alegre PPGAS/UFRGS, v. 8, n. 18, 2002, p.188-209. FapUNIFESP (SciELO).

BECKER, Ítala, Irene, Basile. O Índio Kaingang no Rio Grande do Sul. Pesquisas, Antropologia $n^{\circ} 29$, Instituto Anchiano de Pesquisas, Universidade do Vale do Rio dos Sinos: São Leopoldo, 1976.331p.

BRAGA, Danilo. A história dos Kaingang na luta pela terra no Rio Grande do Sul: do silêncio à reação, à reconquista e a volta para casa. Programa de Pós-

36 Ver notadamente Ramos (2019).

37 Ver o documento final do XV Acampamento Terra Livre. Disponível em $<$ https://mobilizacaonacionalindigena.wordpress.com/2019/04/26/documento-final-do-xv-acampamento-terra-livre/ $>$. Acessado em 11/04/2019. 
-Graduação em História - Universidade Federal do Rio Grande do Sul. (PPGH/ UFRGS), 2015.

BRINGMANN, Sandor Fernando. Entre os índios do sul: Uma análise da atuação indigenista do SPI e de suas propostas de desenvolvimento educacional e agropecuário nos Postos Indígenas Nonoai/RS e Xapecó/SC (1941-1967). Tese (Doutorado em Antropologia Social). Programa de Pós-Graduação em História: Florianópolis, 2015, 452f.

CASTRO, Paulo Afonso de Souza. Ângelo Cretã e a retomada das terras indígenas no sul do Brasil. 161f. Dissertação (Mestrado)- Curso de Antropologia Social, UFPR, Curitiba, 2011.

CLASTRES, Pierre. Do etnocídio. In: Arqueologia da violência. São Paulo: Cosac Naify, 3ra edição, 2014 [1977], p 79-93.

COMUNIDADE KANDÓIA/VOTOURO. Pronunciamento da comunidade Kandóia/Votouro, Espaço Ameríndio. v.8, n.1, 2014.

FERNANDES, Ricardo Cid. Política e Parentesco entre os Kaingang: uma Análise Etnológica. São Paulo: PPGAS/USP, 2003.

GOFFMAN, Erwing. Asiles - Études sur la condition sociale des malades mentaux et autres reclus. Paris: Editions de Minuit, 1968.

IRANI, Miguel Kẽgranh. Ëg sï ag kar pã`ï ag tÿ nén ü veja kãmén ge SPI to Ëmã Inhacorá tá. O Serviço de Proteção ao Índio (SPI) na visão dos anciões e lideranças do povo Kaingang da Terra Indígena Inhacorá (São Valério do Sul, Rio Grande do Sul). Trabalho de Conclusão de Curso (Licenciatura Intercultural Indígena do Sul da Mata Atlântica) Universidade Federal de Santa Catarina: Florianópolis, 2015, $35 f$.

LAROQUE, Luis Fernando da Silva. Lideranças Kaingang no Brasil Meridonial (1808-1889). São Leopoldo. Instituto Anchietano, 2000.

LE GUIN, Ursula K. Los desposeídos. Barcelona. Ediciones Minotauro, 1983 [1974].

LIMA, Antonio Carlos de Souza. Um grande cerco de paz: poder tutelar, indianidade e formação de Estado no Brasil. Petrópolis: Vozes. 1995.

MARÉCHAL, Clémentine. Sonhar, Curar, Lutar: Colonialidade, Xamanismo e Cosmopolítica Kaingang no Rio Grande do Sul. Editora Prismas: Curitiba, 2017. 240p.

MOTA, Lucio Tadeu. As guerras dos índios Kaingang. A história épica dos índios Kaingang no Paraná (1769-1924). Maringa: Editora da Universidade Estadual de Maringá, 1994. 
PACHECO DE OLIVEIRA FILHO. "O nosso governo": os Ticuna e o regime tutelar. São Paulo: Marco Zero. [Brasilia, DF]: MCT/CNPq, 1988.

POZZOBON, Jorge. O lumpen-indigenismo do estado brasileiro. Journal de La Société Des Américanistes, v. 85, n. 1, 1999 p.281-306. PERSEE Program.

QUIJANO, Aníbal. Colonialidad y modernidad/racionalidade. In: BONILLA, Heraclio (org.) Los conquistados: 1492 y la población indígena de las Américas. Quito, Libri Mundi, 1992.

RAMOS, Alcida Rita. Seduzidos e abandonados, ou, como amansar índios rebeldes. Série Antropológica, 462. Universidade de Brasília, 2019.

ROSA, Rogerio Reus Gonçalves da. Os kujá são diferentes: um estudo etnológico do complexo xamânico dos Kaingang da terra indígena Votouro. $416 \mathrm{f}$. Tese (Doutorado) - Curso de Antropologia Social, PPGAS/UFRGS, Porto Alegre, 2005.

TAUSSIG, Michael. Chamanismo, colonialismo y el hombre salvaje: Un estudio sobre el terror y la curación. Bogotá: Universidad del Cauca, 2012. 590 p.

VALENTE, Rubens. Os fuzis e as flechas. História de sangue e resistência indígena na ditadura. São Paulo: Companhia das Letras, 2017.

VEIGA, Juracilda. Cosmologia e práticas rituais Kaingang. Campinas: Unicamp. Tese (Doutorado). - Curso de Antropologia Social. PPGAS/Universidade de Campinas, 2000.

\title{
ETHNOCIDE POLITICS AND RESISTANCE IN KAINGANG RECOVERING LANDS IN RIO GRANDE DO SUL STATE (BRAZIL)
}

\begin{abstract}
This paper proposes to give visibility to the territorial situation of three Kaingang Indigenous Lands in the north of the Brazilian state of Rio Grande do Sul that were not homologated by the Brazilian state yet. The Kaingang recovered these three territories during 2000's years autonomously. The members of these communities are persecuted by local's elites and criminalized by juridical apparatus, which supports economics interests of these elites. That way, this work pretends to points out the mechanisms developed by the official media such as State's representatives and organizations linked with agribusiness that are looking to borrow indigenous memory and life in the regions controlled by them, and to delegitimize, persecute and criminalize Kaingang people who dare to defy them. These several type of violence constitute as a ethnocide politics to which, however, Kaingang people are resisting, fighting with determination to recover their lands,
\end{abstract}


and, with it, a whole series of social, economic and spiritual relationships that were expropriated from them during the different colonial processes.

Keywords: Kaingang. Ethnocide. Agribusiness. Media.

\section{POLÍTICA DEL ETNOCÍDIO Y RESISTENCIA EN LAS RETOMADAS KAINGAN EN EL ESTADO DE RIO GRANDE DEL SUR (BRASIL)}

Resumen: Este artículo propone dar visibilidad a la situación territorial actual de tres Tierras Indígenas Kaingang en el norte de Rio Grande del Sur (Brasil) que todavía no fueron homologadas por el Estado brasileño. Esos tres territorios fueron recuperados en los años 2000 de forma autónoma por los Kaingang. Los miembros de estas comunidades se encuentran perseguidos por las elites locales y criminalizadas por el aparato jurídico del Estado que sostiene los intereses económicos de estas elites. Así, este trabajo pretende resaltar los mecanismos desarrollados, tanto por los medios de comunicación oficiales cuanto por representantes del Estado y de las organizaciones ligadas a la agroindustria, que buscan por un lado apagar la memoria y la vida indígena en las regiones que hoy controlan, y por otro, deslegitimar, perseguir y criminalizar los Kaingang que osan desafiarlos. Estos diversos tipos de violencia se constituyen como una verdadera política del etnocidio a la cual sin embargo, los Kaingang resisten, luchando con determinación para recuperar sus territorios y con estos toda una serie de relaciones sociales, económicas y espirituales que les fueron expropiadas a lo largo de diversos procesos coloniales.

Palabras claves: Kaingang. Etnocídio. Agroindustria. Medios de comunicación. 